Original Article (short paper)

\title{
Strategies to teach swimming to people with Spinal Cord Injury (SCI)
}

\author{
Milena Pedro de Morais ${ }^{1}$ (1), Graciele Massoli Rodrigues ${ }^{2}$ (1) \\ ${ }^{1}$ Universidade São Judas Tadeu, Sao Paulo, SP, Brazil; ${ }^{2}$ Universidade São Judas Tadeu, ESEF, Jundiaí, SP, Brazil
}

\begin{abstract}
Aims: The Swimming has numerous benefits in the physiological, psychological, social and cognitive aspects for the person with spinal cord injury. However, the process of learning the swim must be done in order to take advantage of the potential and the motor functions of the swimmer, through the planning of actions and teaching strategies that seek an effective swim with the fewest adaptations possible and respecting the specific conditions of the lesion. The objective was to verify how the teacher evaluates the motor function of the swimmer with the SCI and to understand how this instructional process acts in the learning of swimming through the perspective of the teacher. Methods: Participated in the research, twelve Physical Education teachers, who work with spinal cord injury swimmers. Data were collected through semi-structured interviews and a field diary. Results: The results demonstrated that, depending on the teaching style adopted by the teacher, he does not consider the student's feedback and perception. $\mathrm{He}$ acts only on the results and possibilities he sees. Therefore, in the teacher's view, the adaptability of the swimming technique is conditioned to the motor limitation of the individual with SCI, or according to the teacher's perspective on the functionality. Conclusion: We conclude that the use of strategies based on the traditional swimming technique showed that there is little awareness or lack of knowledge about the work of promoting the swimmer's motor function, confirmed to the extent that the contribution of the specific literature is incipient and does not satisfy the teacher's desire for knowledge.
\end{abstract}

Keywords: teaching strategies; spinal cord injury; swimming; motor functionality.

\section{Introduction}

Multiple aspects related to the psychosocial benefits to people with SCI have been discussed by the scholarly literature. Among them, one can find mental health, socialization, quality of life, heart hypertrophy, maximum oxygen uptake improvement, maximum lactate level and pulmonary function. Additionally, there are neurological benefits such as the effect on the activity of the synaptic neuron that facilitates the myelination and the remyelination processes due to the muscle contraction ${ }^{1,2}$. This occurs because the voluntary motor training demands the right conditions of muscle tonus and asks for afferent feedback, which is designated by a neuromotor answer of the sensory function ${ }^{3}$.

People with SCI begin to swim in the clinical rehabilitation process, due to the high index of lesions acquired. The sport has assumed the auxiliary function in this process, making the educational purpose essential. Therefore, the selection of adequate strategies during the teaching process mediated by the teacher acts to promote the motor function of the swimmer with SCI. This is the assumption for the adaptation process as a medium to encourage various possibilities of movement that could contribute to the process of teaching/learning, improving the quality of living for people with $\mathrm{SCI}^{4}$.

The success of the activity is due to specific factors in the teacher professional practice: to know the SCI characteristics influencing the teaching/learning of the swimming process, as per example, the flotation, as people with SCI have high floating potential only in the lower limbs, and while they float effortlessly, they often have difficulty to come back to the upright position ${ }^{5,6}$.

In the scholar field there is a lack of strategies for teaching swimming to individuals with SCI, therefore it is clear the relevance to understanding in-depth the motor skills in the teaching/learning process, which is directly linked to the practice the teacher uses and to the learning by the pupil as an active part in this process.

In this sense, this study aims to verify: How the teacher assesses the motor function of the swimmer with SCI, and the perspective of teachers on how the pedagogical process acts in the learning of swimming.

\section{Materials and methods}

This is a descriptive exploratory qualitative research ${ }^{7}$. The respondents were twelve teachers of swimming, working for at least one year with people with SCI. Teachers of swimmers with spinal pathologies without functional involvement in the list of mono, di, tri, para and quadriplegia, hemiplegia and paresis were excluded from this research. The data collection was done through a semi-structured interview, composed of nine themes covering the problems and objectives of the research.

The interviews were pre-scheduled, recorded and transcribed. The data were submitted to a content analysis ${ }^{10}$, as per, and seven categories of themes were identified: Swimming (standard and for people with SCI), Condition's overcoming and driving to 
the rehabilitation of the swimmer with SCI, Structure of the intervention, Swimming for people with SCI: teaching process, adequacy to the needs and strategy, Teacher's understanding of the functionality, Teacher and pupil's functionality and the contribution and support of the professional.

To collect the data, it was also used a field diary consisting of a form with the teacher's personal information and ID, description of the focused pupil (time of practice, age, characteristics of the injury), objectives of the class and a specific field for the activities developed, followed by questions about the strategies used to teach them. There were eight activities options: Breathing, Dorsal buoyance, Ventral buoyance, The transition from dorsal to a ventral position, The transition from ventral to a dorsal position, Hip rotation from ventral to a dorsal position, Hip rotation from dorsal to a ventral position and Arm back/forward rotation. The diary also had a space for two other activities conducted by the teacher. All the teachers' notes about the teaching strategies used, monitoring the pupils and use of the pedagogical material were submitted to the descriptive analysis.

The research was approved by the Ethics and Research Committee of the Universidade São Judas Tadeu under number 859.397.

\section{Results}

In the Standard Swimming category and for people with SCI the differences between the two modalities of swimming were discussed. These difficulties are also related to the overcoming condition and driving to the rehabilitation of the swimmer with SCI, because of his/her/family expectations at the beginning of the swimming learning process, but also related to technical and methodological aspects of swimming for people with SCI.

This teaching process has different characteristics when compared to the regular swimming, as they represent a paradigm break, because each person with SCI has his/her pattern of swimming, whereas for the regular swimming the preoccupation is only with the technical execution of the movement.

"Family and teacher create expectations about the learning of the pupil, for whom is very important to believe that he/she has potential (...)"

Teachers discussed this aspect as it is essential to consider both the pupil's individuality and respect his/her timing to learn. The teacher wants to help the pupil in his post-traumatic period, facilitating the discovery of his/her potentials and the process of recognition of a new life, the perception of a new body as a factor that promotes a change in the pupil's mindset regarding what means to be a disabled person.

"It is amazing when they discover the movement, their functional capacity, it is a transformation because they come thinking that they will not get a great deal, and then they find out that their bodies can do much more than the movement they do in a wheelchair".

In the Structure of the Intervention category, classes' schedule and individual attention to the pupil are as important as the previous assessment to facilitate the teaching process.

The Swimming for People with SCI category: the teaching process, the suitability to the needs and the strategy highlighted that the phase of adaptation to the water is essential to the development of the pupil's perception about the functionality of the movement. It has been found that the strategies of teaching can occur in many forms and that teachers select them according to the level of learning, the pupils' degree of injury and the vision of the teacher on the functionality. This last aspect is crucial in order to make an adjustment to their needs and to recognize their potentials.

The teaching process guidance could be oriented either to the pupil's potentials or to the limiting view of the accomplishment of tasks. The work of the teacher is to make the needed adaptation so that the pupil responds to a particular purpose, restricted and specific about the activity to be developed.

Considering the aspects above mentioned, the teaching process should value the potentials of the pupil, focusing on the skills development and not in the impairment. Adaptations and strategies in teaching should be thought as to consider the singularities of each student and the feedback given to the teacher, who should devise the teaching strategy with the pupil and respect his/her pattern of swimming regarding balance, propulsion, drag, and buoyancy.

The process to determine the strategy is linked to the many factors inherent to the swimming practice, as the teacher's ability to work with a person with SCI, his assessment on the limitation and inability of the pupil to perform determined task and the development of a strategy that makes it possible to accomplish the task considering the limitations of the disability. In fact, it considering the problematic point of start's teaching process because the people with SCI sometimes are responsible to adapt their movement. It was clear that in order to recognize the potentials of the pupil with SCI it is necessary to make a comparison with the regular swimming and the importance of the teacher as a mediator in the process to discover the functionality.

The item Understanding of the Teacher about the functionality, specifically about how much the person with SCI can do, it depends on the expectations one has, on the stimulus is given or how much the teacher sees and recognizes the extent of the pupil's potentials.

When working with the teacher as a team, the pupil gives feedback, and becomes aware of his/her own body and discovers and builds the better way to move, and the more efficient way to do it. The functionality was discussed as a set of actions and a shift from the view of the limitation when the pupil discovers his/her potentials.

\footnotetext{
“(...) a great part of their lives is out of the swimming pool, the move they do in water is different from the one they do out of the water and... it is this way;
} 
they think that they cannot move the arm or the upper body when in the wheelchair, but when they make a motor action in the water they perceive a functionality of something that before did not have a function for them".

The discovery of the potentials does not occur only in the pupil's vision, it happens in the perception and in the teacher's analysis of the teaching process. Teachers affirmed that the autonomy of the pupil is relevant for the discovery of potentials, which should be rebuilt because of the disability and need for support, the pupil ceases being autonomous and becomes dependent on others. The work to discover the potentials begins in the planning of the teacher's instruction, which should make the pupil, feel safe and evolve in the learning.

In Teacher and the Functionality of the Pupil it was explicit that the teacher acts according to his/her principles, not considering the pupil's feedback as relevant information for the building of the educational activities. In addition, this issue is associated with the style of teaching adopted by the teacher.

The teacher associates the perception of the functionality with the degree of motor involvement of the pupil and considers the neurological vision of the function, differentiating between the ability to have functionality in complete and incomplete injuries, thus associating the functional perception to the technical efficiency of the movement in the swimming, and to the perception of sensitivity.

Nevertheless, the functional perception becomes clearer to the teacher when the pupil shows motor perception before SCI, and he/she guarantees the maximum use of the pupil's mobility. In this case, it is the professor duty to recognize the potentials and use strategies that could contribute to the learning and development of the functionality.

However, the lack of specific literature related to swimming for people with SCI implies that teachers use the documentation for conventional swimming, which was pointed out in Professional Input and Support.

Data obtained in the field diary allowed us to verify the conduction of the teaching process according to the learning phase of the pupil and to his/her level of SCI, and how the instructional process acts in the learning, being all these factors associated to the intended activity and objectives for both teacher and pupil.

In respect to the Guidance and Use of Strategies of Teaching, as will be described below, it was observed that they are differentiated depending upon the action to be done and the desired objective, being listed twenty different goals by the ten participants. Among the objectives, there are: the pupil should complete $100 \mathrm{~m}$ backstrokes, physical preparation, and conditioning improvement, adaptation to the water and introductory course to crawl and backstrokes, development of the techniques of crawl swimming, increase the glaze and the dorsal buoyancy during the double stroke, among others.

For the activity Breathing, the teachers told that they use as teaching strategy visual demonstration and oral instruction. In dorsal and ventral buoyance, teachers reported to be underwater to help the pupil physically or with a flotation material as an auxiliary resource, as well as in the activities of transition from ventral to dorsal position and vice-versa, and in the latter they use balls and the edge of the pool.

In the Conduction and Execution of the Activity, the strategy used was to guide pupils to discover the body balance, using variations of the balance position added to the concentration of the strength in the muscle contraction in the abdominal region to move with the help of the edge of the pool.

It was noticed that teachers did not use flotation material as a facilitator to teach hip rotation in decubitus change, as they recurrently use their own body as a physical support to the pupils, leading us to understand that the use of the floating material in this movement could not be a facilitator, as it prevents the free movement of the pupil in the water, substantiating the teacher's direct assistance.

For Arm Rotation Backwards and Forward activities, the buoy material mentioned was the board and the acqua tub. As conduction strategy, besides the demonstration of the movement, teachers ask another student to be the model of the movement to be done. During all the process of teaching, we identified that verbal instruction was primarily used and complemented by other strategies, created or not by the teacher.

\section{Discussion}

Teacher's participation and engagement not only in class but in the relation with the life of the learner is the key to promote significant changes and sets the difference between the regular swimming and the one for people with SCI. In this sense, what makes the professional working with a disabled person different is the construction of actions about himself and the other through the challenges of the practice of sports.

The psychosocial well-being is essential to overcome challenges, and the practice of sports has a relevant role in this aspect, as the family has high expectations about the success of the actions that could improve the quality of life and the motor potentials of the person injured. About these expectations, it is often difficult to deal with technical and methodological aspects of swimming for a person with SCI, as there is a swimming model socially recognized and it is the regular swimming, with four styles and typically associated to a predetermined sequence of apprenticeship ${ }^{8}$.

The man should be seen in his entirety ${ }^{9}$, as much as an individual able to develop and as per his uniqueness. Therefore, it is important to consider the pupil's individuality as independent of the context may it be inclusive or not, prioritizing the potentiation of the movement, which is characterized by the discovering of the functionality and the total use of the residual potential, being the teaching strategies the main point for adequacy to the needs and the recognition of the pupil's possibilities ${ }^{11}$.

The target of the teaching process could be directed to the pupil's potentials or to the limiting accomplishment of tasks, and the teacher must make the necessary adaptations so that the pupil answers to a specific purpose related to the activity to be developed. 
Despite the disability, the activity to be done and the environment are important factors to be considered in the teaching process, the focus should be the development of skills ${ }^{12}$. The emphasis should be in the building of a positive attitude of the professional and in the demystification of the impairment, critical aspects in a teaching program specific to the adapted physical activity ${ }^{13}$. Those health professionals should maintain the focus in the attendance of the person with SCI, developing the maximum potential for the health and functions through the swimming. That it is essential to consider the motor functionality of the person with SCI, as it will define the social and cultural expectations about life ${ }^{14}$

It can be stated in the view ${ }^{11,14}$ about the valuation of the potentials of the pupil and the emphasis in the building of a teaching process that leads to the skills development. In contrast $^{15}$, "it is important that the teacher has full knowledge of lost or damaged functions of each pupil so that he can define specific objectives". In this vision, the teaching focus is in the limitation of movements in consequence of the disability, thus prioritizing the spinal cord injury, disregarding the individual's potentials.

From the perspective of the pupil's potentials, the necessary adaptations and strategies to be used are considered according to the specificities of each pupil, and the feedback to the teacher should be assessed during the activities ${ }^{14}$, the teacher should plan with the pupil which strategy of teaching will be more comfortable for the development of the activities.

Thus, the process to determine the strategy is linked to the various factors inherent to the swimming practice, i.e., the teacher's skill to work with a person with SCI, his analysis about the pupil's limitations and disability for a determined task and the setting of a strategy to perform a task considering the boundaries of the disability.

The responsibility of the teacher is to promote the learning according to his vision about the functionality and to use proper strategies of teaching, the ones that could foster the needed stimulation. The focus should be on the teaching program (curriculum, content, strategies, procedures, materials and resources, places and environment of the intervention, assessment and learning methods) and not only about the disability ${ }^{15}$.

This question is related to the teaching style that could be by orders, by tasks, by guided discovery or by the problem-solving approach. In this way, the style adopted interferes directly with the pupil's learning, in the case that the style does not fit the needs shown ${ }^{16}$.

Thus, the teacher has to guarantee maximum achievement of the pupil's mobility, to recognize his/her potentials and to use strategies that could contribute to the learning and to the development of the functionality. We observed a discontinuity in the teacher's discourse about the view and interpretation they build about the functionality when their pupils move. That discontinuity brings them near the "sportivization" of the movement (adding elements that are intrinsic to conventional sports, like competitivity and performance) following the knowledge recently produced. So, while the sports approach for teaching swimming technically answers to the questions of the sportivization of the pedagogical practice without preoccupation with the teacher's instruction and feedback as regards to the adaptability of the pupil in the triad body, environment, and task, this sports approach will continue to prevail and excluding those who do not "fit" in the shape of the practice ${ }^{17}$.

\section{Conclusion}

It was observed that depending on the teacher's style of teaching, the feedback of the pupil and the possibilities that it can open are not considered. This disregard means that in the perspective of the teacher about the swimming technique, the adaptability is conditioned to the motor limitation of the individual with SCI or to the teacher's vision about the functionality as a set of factors.

It becomes clear that to recognize or not the potentials of the individual with SCI interferes directly in the efficiency of the teaching process and the teacher's practice in a manner that from the moment in which this recognition occurs, a wide range of options and teaching strategies are feasible.

As far as the teaching strategies, the use of procedures based on the traditional technique of swimming showed that there is low sensitization or even lack of knowledge about the work of promoting the motor function of the swimmer. The latter is confirmed by the scarcity of literature about the theme, which does not satisfy the teacher's desire for knowledge. It is important to highlight that the discussion was guided by the view of functionality provided by the potentials of individuals with SCI, and how much and in which form it is related to the neurologic aspect of the function.

\section{References}

1. Sadowski CL, Mcdonald JW. Activity-based restorative therapies: concepts and applications in spinal cord injury-related neurorehabilitation. Dev Disabil Res Rev. 2009;15(2):112-615: doi: 10.1002/ ddrr.61.

2. Buchholz AC, Martin Ginis KA, Bray SR, Craven BC, Hicks AL, Hayes $\mathrm{KC}$, et al. Greater daily leisure time physical activity is associated with lower chronic disease risk in adults with spinal cord injury. Appl Physiol Nutr Metab. 2009;Aug;34(4):640-7; doi: 10.1139/H09-050.

3. Franz M, Richner L, Wirz M, von Reumont A, Bergner U, Herzog $\mathrm{T}$, et al. Physical therapy is targeted and adjusted over time for the rehabilitation of locomotor function in acute spinal cord injury interventions in physical and sports therapy. Spinal Cord. 2018;Feb;56(2):158-167.doi.org/10.1038/s41393-017-0007-5.

4. Sale P, Mazzarella F, Pagliacci MC, Aito S, Agosti M, Franceschini M. Sport, free time and hobbies in people with spinal cord injury. Spinal Cord. 2012;Jun;50(6):452-6. doi: 10.1038/sc.2011.

5. Giraldo AED, Picareli, C, Souza EC, Iasi, TCP. Atividades aquáticas adaptadas. ADAPTA. 2010;1(6): 72-73.

6. Vitor A, Elzo J, Cecarelli L, Barbanera P. Atividades aquáticas adaptadas. ADAPTA. 2010; 1(6): 72-73.

7. Thomas, JR, Nelson, J. K. Métodos de pesquisa em atividade física. Ed ArtMed, Porto Alegre, 2002. 
8. Bardin L. Análise de conteúdo. Edições 70, Lisboa, 2011.

9. Precin P. Influência dos fatores psicossociais na reabilitação. In: Fisioterapia: Avaliação e Treinamento. Ed. Manole, Barueri; 2010. p. 27-69.

10. Pedrinelli VJ, Verenguer RC. Educação Física Adaptada: introdução ao universo das possibilidades. In: Atividade Física Adaptada: Qualidade de vida para pessoas com necessidades especiais. Ed. Manole, Barueri, SP; 2008. p. 148-181.

11. Greguol M. Natação Adaptada em busca do movimento com autonomia. Ed. Manole, Barueri, São Paulo, 2010.

12. Emes C, Longmuir P, Downs P. An Abilities-Based Approach to Service Delivery and Professional Preparation in Adapted Physical Activity. Adapt Phys Activ Q. 2002;19(4):403- 419. doi: 10.1123/ apaq.19.4.403.

13. Giesecke C. Aquatic Rehabilitation of Clients with Spinal Cord Injury. In: Aquatic Rehabilitation. Ed. Lippincott, New York, USA; 1997. p.127-150.

14. Guccione AA, Scalzitti DA. Avaliação do estado funcional e do nível de atividade. In: Fisioterapia: Avaliação e Treinamento. Ed. Manole, Barueri; 2010. p. 404-425.

15. Gorgatti MG, Bohme MTS. Atividade Física e a Lesão Medular. In: Atividade Física Adaptada: Qualidade de vida para pessoas com necessidades especiais. Ed Manole, Barueri, São Paulo, 2008.
16. Munster MAV; Almeida J.J.G. Um olhar sobre a Inclusão de pessoas com Deficiência em Programas de Atividade Motora: do espelho ao caleidoscópio. In:Atividade motora adaptada: a alegria do corpo. Artes Médicas, São Paulo, 2006. p. 81-91.

17. Melo A. C. R. Descrição da Aptidão inicial para natação em lesados medulares. Rev Bras Med Esporte. 2009;6(15):441- 445.

\section{Corresponding author}

Milena Pedro de Morais

Rua Jaci, 45. Balneário Tupi - Itanhaém, São Paulo, Brasil, CEP 11740-000

E-mail: milena.educacaofisica@gmail.com

Manuscript received on June 6, 2018

Manuscript accepted on August 22, 2018

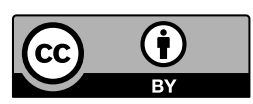

Motriz. The Journal of Physical Education. UNESP. Rio Claro, SP, Brazil - eISSN: 1980-6574 - under a license Creative Commons - Version 3.0 